\title{
Field Tests on the Attenuation Characteristics of the Blast Air Waves in a Long Road Tunnel: A Case Study
}

\author{
Yong Fang $\mathbb{D}$, Yi-Lun Zou $\mathbb{D}^{D}$, Jian Zhou, Zhi-gang Yao $\mathbb{D}$, Shuai Lei, and Wenbo Yang $\mathbb{D}$ \\ Key Laboratory of Transportation Tunnel Engineering, Southwest Jiaotong University, Ministry of Education, Chengdu, China \\ Correspondence should be addressed to Wenbo Yang; yangwenbo1179@hotmail.com
}

Received 30 December 2018; Revised 16 March 2019; Accepted 3 April 2019; Published 24 April 2019

Academic Editor: M. I. Herreros

Copyright (C) 2019 Yong Fang et al. This is an open access article distributed under the Creative Commons Attribution License, which permits unrestricted use, distribution, and reproduction in any medium, provided the original work is properly cited.

\begin{abstract}
After an explosion occurs in a tunnel, the blast waves take on diverse forms of attenuation in different regions when it propagates along the tunnel. However, the prediction of the overpressure decay laws proposed in previous studies has not taken into account the influence of the different regions in the tunnel. The present paper uses the example of the Micangshan highway tunnel in China and considers many factors that influence the propagation of the blast waves by dividing the tunnel into four zones. The paper modifies the decay equation proposed by Smith and applies it to the Micangshan highway tunnel in China. The decay equations are different in different zones. Field tests in this tunnel show that the modified equation is more suitable to describe the attenuation of the blast waves in the tunnel than the original equation.
\end{abstract}

\section{Introduction}

The drilling and blasting method is widely used in the excavation of mountain tunnels. During the advancing of a tunnel, there are two major problems due to the blasting: vibration and shock wave (or air blast wave). Blast-induced vibration affects the stability of surrounding rocks and threatens the safety of neighboring buildings or structures. Numerous studies have been published on the responses and damage to structures subjected to blastinduced vibration [1-4]. Most of the explosive energy is consumed in breaking the rocks, causing the vibration and throwing out the fragments. A small remaining part of the energy enters the surrounding air through the gaps, compresses the air, and creates the air blast waves $[5,6]$. The air blast waves threaten the safety of personnel and equipment in the tunnel $[5,7,8]$. During the blasting operation, the personnel and properties have to be evacuated far away from the advancing face to avoid the threat of the air blast waves. This evacuation and subsequent recovery takes a lot of time that is unendurable, especially for an extralong tunnel. Hence, it is very important to determine the safe distance from the explosion for the properties and personnel.
Many studies of the propagation of air blast waves induced by the detonation of explosive charges have been done in free fields, where the blast waves propagate freely in the atmosphere. Baker et al. [7], Brode [9], and Henrych [10] proposed general fitting laws to describe the relationship between the maximum overpressure peak and the distance to the explosive charge. Ishikawa and Beppu [11] summarized some lessons about the negative air blast waves of explosions over structures from explosive tests. Using the Computational Fluid Dynamics (CFD) method, Chapman et al. [12] simulated the propagation of an air blast wave in a two-dimensional free field. Wu and Hao [13] built a 3D model to simulate the effects of an explosion on neighboring structures, considering the ground vibration and air blast wave at the same time. Casal and Salla [14] and Genova et al. [15] also defined the peak intensity of the boiling liquid expanding vapour explosion (BLEVE) blast wave in a free field.

The propagation of blast waves in a free field is different from that in a tunnel, which is a confined environment. Although the negative effects of the air blast wave on structures have been studied for many years, there are not many studies set in underground environments. Smith et al. [16] described a series of scaled model tests of blasting loading and suggested that scaled models can provide a useful means 
of obtaining blast loading data for complex structures. Smith et al. [17] also conducted a scaled model test of the blast wave propagation along straight tunnels and revealed that the roughness of the tunnel walls has significant effects on the blast wave propagation. Li and Zheng [18] conducted scaled model tests to investigate the air blast propagation down the tunnel and developed empirical equations to predict the intunnel air blast pressure induced by detonations that are external, internal, and at the entrance.

Recently, the CFD method has been widely used to investigate the propagation of air blast waves induced by dense explosives in confined complex geometries [19-22]. Using a numerical method, Liu et al. [23] investigated blast wave propagation near the explosion site inside a tunnel. Benselama et al. [24] and Uystepruyst and Monnoyer [25] revealed that the air blast waves in a tunnel have two patterns: a free-field overpressure decay pattern near the explosion site and a quasi-one-dimensional pattern far from the explosion. They proposed a correlation law by a numerical study to define the transition distance according to the explosive charge and the geometry of the propagating domain. Pennetier et al. [26] conducted a scaled model test and numerical simulation of blast waves in tunnels and found that the data of the experimental tests fit well with the numerical simulation. In field tests, Rodríguez et al. [6, 27] developed a semiempirical model to predict the air wave pressure and sound level outside a tunnel due to the blasting inside. A series of explosive detonation experiments was conducted in NIOSH's Bruceton and Lake Lynn Experimental Mines to evaluate the blast wave propagation in underground mines, and a simple scaling relationship of the peak overpressure with the explosive charge and the propagation domain was proposed [28, 29].

Nevertheless, there are little published experimental data about blast wave propagation in tunnels. This paper intends to use field test data to determine a simple law to predict the overpressure decay in a long tunnel. This has great importance to prevent the threat of blast waves in a long tunnel for personnel and properties.

\section{Blast Wave Propagation in a Tunnel}

Near the explosion charge, the blast waves propagate freely in the atmosphere, as shown in Figure 1(a). The most common free-field decay law proposed by Henrych [10] can be used to relate the maximum overpressure peak (in $\mathrm{Pa}) \Delta p$ to the distance from the explosive charge, which is shown as follows:

$$
\Delta p=10^{6} \times \begin{cases}\frac{1.4072}{Z}+\frac{0.554}{Z^{2}}-\frac{0.0357}{Z^{3}}+\frac{0.000625}{Z^{4}}, & \text { if } 0.05 \leq Z \leq 0.3, \\ \frac{0.6194}{Z}-\frac{0.0326}{Z^{2}}+\frac{0.2132}{Z^{3}}, & \text { if } 0.3 \leq Z \leq 1, \\ \frac{0.0662}{Z}+\frac{0.405}{Z^{2}}+\frac{0.3288}{Z^{3}}, & \text { if } 1 \leq Z \leq 10,\end{cases}
$$

$$
Z=\frac{x}{\sqrt[3]{Q}}
$$

where $Q$ is the explosive charge (in $\mathrm{kg}$ ) and $x$ is the distance from the explosion point to the measurement point (in $\mathrm{m}$ ). However, in the tunnel far away from the explosion, the blast waves can be considered to propagate in a quasi-one-dimensional pattern, as shown in Figure 1(b). Benselama et al. [24] proposed a fitting law to distinguish the discontinuity location $Z_{\text {Trans }}$ where the blast wave propagation pattern transforms into

$$
Z_{\text {Trans }}=\frac{0.0509}{(\alpha / 100)^{13 / 9}}
$$

where the parameter $\alpha$ represents the ratio of the explosive diameter to the tunnel's hydraulic diameter. If the parameter $Z$ in equation (1) is bigger than $Z_{\text {Trans }}$, the blast waves in the tunnel can be considered to propagate in a quasi-one-dimensional pattern, as shown in Figure 1(c).

The following empirical law can also be used to predict the overpressure decay in the tunnel:

$$
\Delta p=\left(a \cdot \frac{m \cdot Q}{S \cdot x}+b \cdot \sqrt{\frac{m \cdot Q}{S \cdot x}}\right) \cdot e^{-n(x / d)},
$$

where $\Delta p$ is the maximum overpressure (in $\mathrm{Pa}$ ) at a measurement point; $Q$ is the explosive charge per delay (in $\mathrm{kg}$ ); $S$ is the area of cross section of the tunnel (in $\mathrm{m}^{2}$ ); $x$ is the distance from the explosion point to the measurement point (in $\mathrm{m}$ ); and $d$ is the equivalent diameter of the cross section of the tunnel (in $\mathrm{m}$ ). The parameters $a, b, m$, and $n$ have to be estimated by experience. Kuzyk [30] suggested the parameters $a$ and $b$ to be 2900000 and 730000 , respectively, while the Chinese government's Enforceable Handbook of Safety Regulations for Blasting [5] suggested the parameters $a$ and $b$ to be 3270000 and 780000 , respectively. The parameter $m$ represents the amount of explosive energy converted to the air blast waves, and the parameter $n$ represents the attenuation of the maximum overpressure with the distance $x$. Rodríguez et al. $[6,27]$ regarded $m$ as a constant value 0.4 and $n$ as a variate less than 0.15 and changing with the distance $x$. However, in the Enforceable Handbook of Safety Regulations for Blasting [5], the parameter $m$ is suggested to be $0.05 \sim 0.1$ for drilling and blasting to advance the tunnel, and the parameter $n$ represents the surface roughness coefficient of the wall.

Smith and Sapko [29] investigated the blast wave propagation in underground mine entries by experiment and put forward the simple decay relationship between the maximum peak overpressure $\Delta p$ and the pentolite explosive charge $Q$ and the volume of the propagation domain $V$ :

$$
\Delta p=A \cdot\left(\frac{Q}{V}\right)^{\beta}
$$

By fitting the experimental data to the equation, the parameter $A$ and the exponential $\beta$ were suggested to be 702800 and 0.514 , respectively [29]. This simple correlation for a single entry fits the data quite well for experimental overpressures from 5 to $50 \mathrm{kPa}$. Silvestrini et al. [31] adopted the energy concentration factor (ECF) to extend the decay laws for open-space detonation of a TNT charge to one-dimensional 


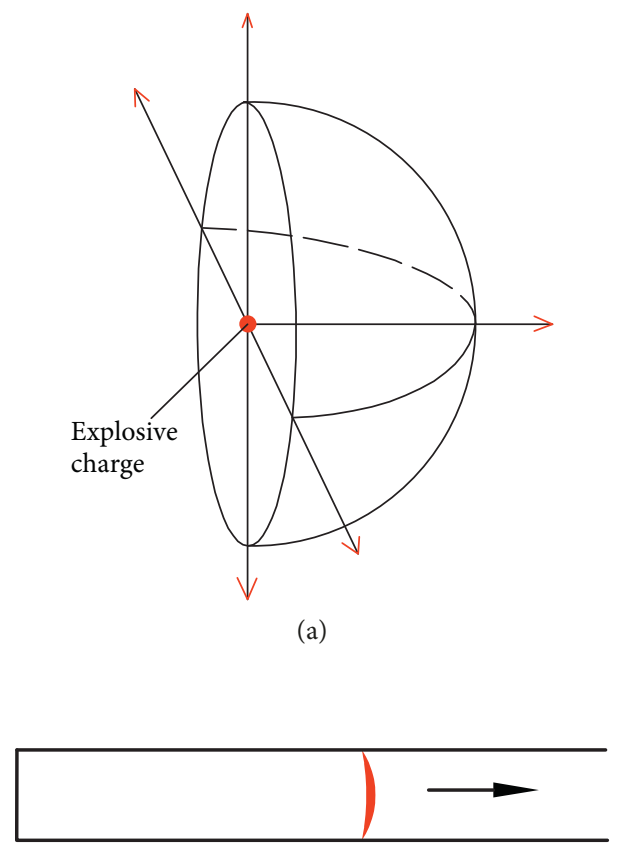

(b)

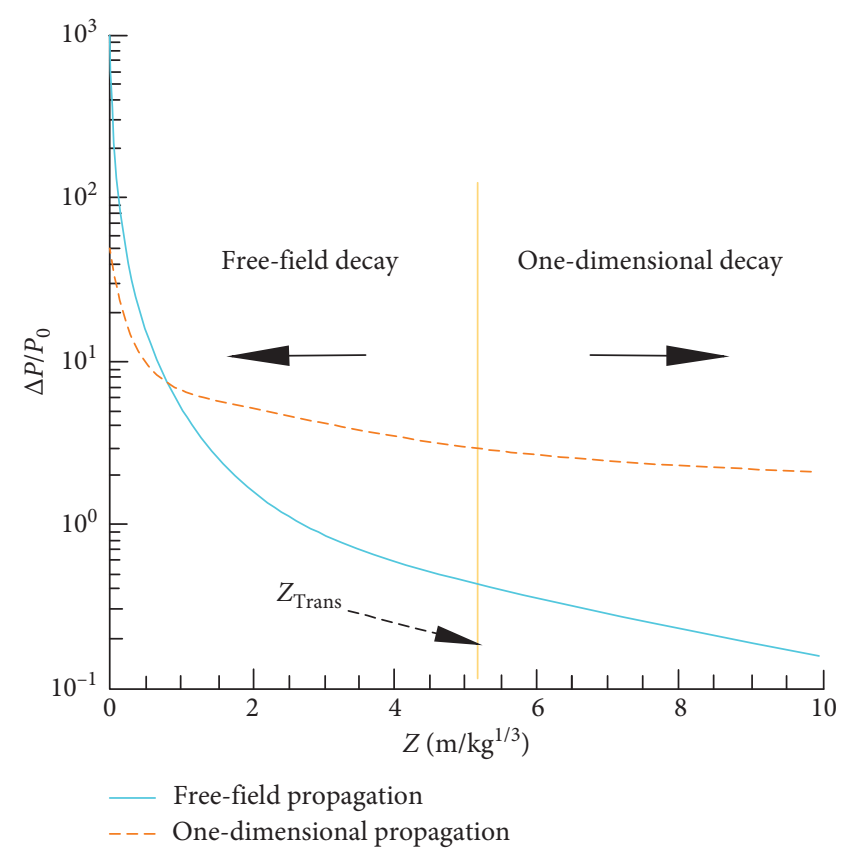

(c)

Figure 1: Blast wave propagation in a tunnel: (a) propagation near the face, (b) propagation far away from the face, and (c) the decay of overpressure along the tunnel $[24,30]$.

propagation in a tunnel with one closed end and suggested the parameter $A$ and the exponential $\beta$ to be 743538 and 0.51 .

However, equation (5) has to be modified because the explosive energy cannot be all converted to the air blast waves and the difference of the kind of explosive. Referring to equation (4) proposed by Kuzyk [30], the parameter $m$ is added to the numerator. The parameter $\lambda$ is the TNT equivalent coefficient. The modified equation is as follows:

$$
\Delta p=A \cdot\left(\frac{m \cdot \lambda \cdot Q}{V}\right)^{\beta}
$$

where the parameter $m$ represents the amount of explosive energy converted to the air blast wave and the exponential $\beta$ represents the attenuation of the maximum overpressure. The parameter $\lambda$ has been found in previous studies to be 0.6 for the emulsion explosive commonly used in tunneling [32]. The parameter $m$ was regarded by Rodríguez et al. as a constant value $0.4[6,27]$. However, the exponential $\beta$ is more difficult to determine because the heading face blasting and blast wave propagation are more complicated in a real tunnel. This paper intends to determine the exponential $\beta$ when equation (6) is used to predict the overpressure induced by blasting in a road tunnel.

\section{The Attenuation of Overpressure in a Road Tunnel}

The investigation of the overpressure attenuation was carried out in the Micangshan highway tunnel in Western China. The tunnel is $13.8 \mathrm{~km}$ in length and was constructed by the New Austrian tunneling method (NATM). Figure 2 shows the profiles of the Micangshan highway tunnel close to the explosion site. According to the change of the cross section, roughness of the wall, and the obstacles in the tunnel, the propagation area of the blast waves in a road tunnel can be divided into four zones. In Zone I, the secondary lining has not been casted. The tunnel has rough and uneven walls, and the area of the cross section is about $77.98 \mathrm{~m}^{2}$. In Zone II, the secondary lining is being casted. The cross-sectional area and wall roughness change suddenly. There are much equipment placed in Zone II, such as the framework of the secondary lining casting, loaders, and drilling jumbo evacuated from the heading face. These equipment also affect the blast wave propagation and cause additional attenuation of the overpressure. In Zone III, the secondary lining has been casted, and the area of the cross section is about $62.5 \mathrm{~m}^{2}$. Generally, the overpressure has a light attenuation in this area as the secondary lining has a smooth, flat surface [17]. Zone IV has an enlarged cross section which is generally used in a long road tunnel as an emergency parking strip. In this area, the cross-sectional area increases from $62.5 \mathrm{~m}^{2}$ to $84.1 \mathrm{~m}^{2}$, then decreases back to $62.5 \mathrm{~m}^{2}$. Some equipment like air compressors and ventilators are placed in Zone IV. In the middle of Zone IV, there is a cross aisle leading to another twin tunnel. Not only the change of the cross-sectional area but also the branch of the tunnel causes great attenuation of the overpressure in this zone [29]. Behind the Zone IV, the form of cross section is the repetition of Zone III and Zone IV.

The attenuation of overpressure in the tunnel comes from resistance during the propagation. The exponential $\beta$ which represents the attenuation of the overpressure in equations (5) and (6) is related to many factors, such as the change of cross- 

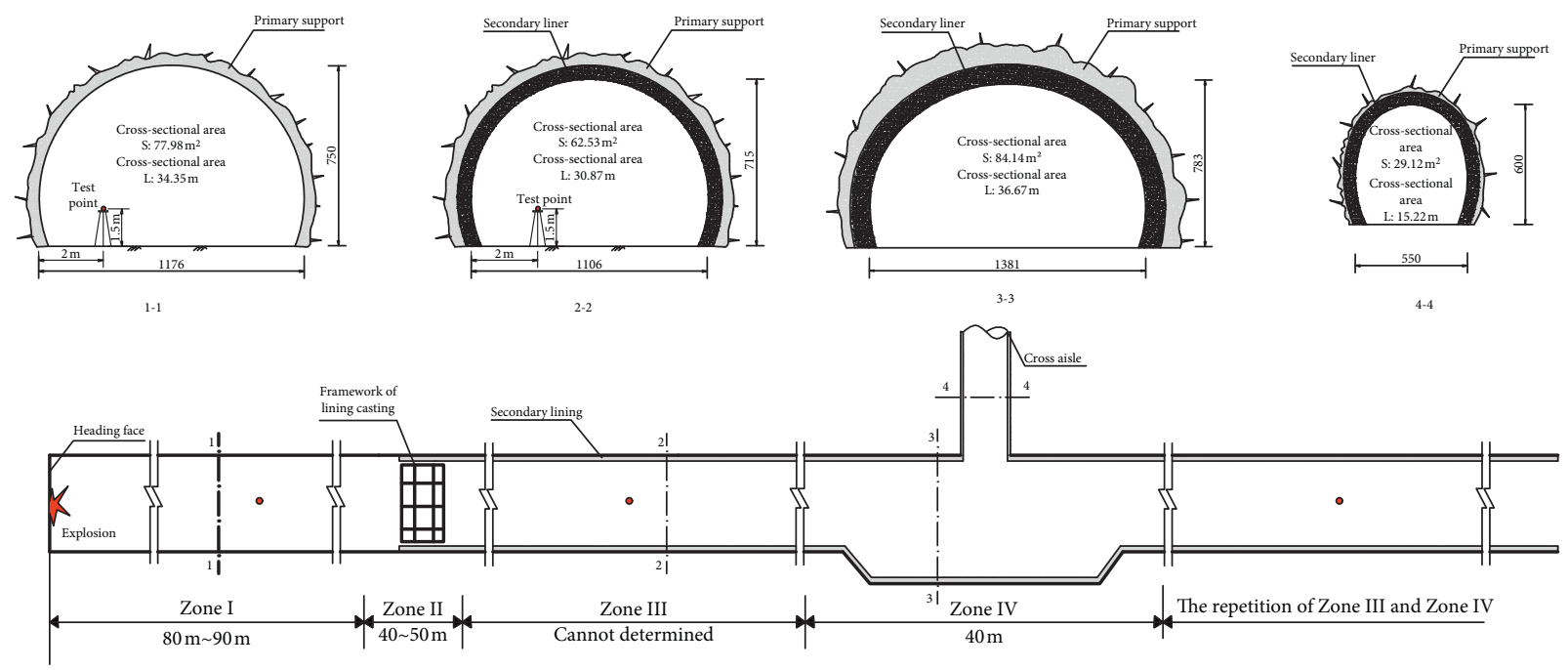

Figure 2: Profiles of the Micangshan highway tunnel near the explosion site.

sectional area, roughness of the wall, and the obstacles in the tunnel. Consequently, a constant value of the exponential $\beta$ cannot represent all the conditions along the road tunnel. Considering these influence factors, the attenuation of overpressure along the road tunnel can be classified as four types:

$\beta_{1}$ : attenuation in the tunnel with primary support, i.e., Zone I, where the tunnel has larger profiles and rough walls.

$\beta_{2}$ : attenuation in Zone II, where the cross section shrinks suddenly as the secondary lining is casted. It can also reflect the influence of the equipment placed in this area on the blast wave propagation.

$\beta_{3}$ : attenuation in the tunnel with secondary lining, such as Zone III, where the tunnel has smaller profiles and flat walls.

$\beta_{4}$ : attenuation in Zone IV, where the tunnel has an enlarged cross section. It can also reflect the influence of the equipment and the cross aisle on the blast wave propagation.

The overpressure along the tunnel can be predicted using these attenuation parameters. The overpressure in Zone I can be predicted by equation (6) after the parameters are determined. At the end of Zone I or the beginning of Zone II, the overpressure can be expressed as

$$
\Delta p_{\mathrm{I}}=A \cdot\left(\frac{m \cdot \lambda \cdot \mathrm{Q}}{V_{\mathrm{I}}}\right)^{\beta_{1}}
$$

where $V_{\mathrm{I}}$ is the whole volume of Zone I. Similarly, the overpressure at the end of Zone II or the beginning of Zone III can be expressed as

$$
\Delta p_{\mathrm{II}}=\Delta p_{\mathrm{I}} \cdot\left(\frac{V_{\mathrm{I}}}{V_{\mathrm{I}}+V_{\mathrm{II}}}\right)^{\beta_{2}},
$$

where $V_{\text {II }}$ is the whole volume of Zone II. Then, the overpressure in Zone III can be expressed by the attenuation of the overpressure at the beginning of Zone III as

$$
\Delta p=\Delta p_{\mathrm{II}} \cdot\left(\frac{V_{\mathrm{I}}+V_{\mathrm{II}}}{V}\right)^{\beta_{3}},
$$

where $V$ is the whole volume of the propagation domain. Equation (9) can be rewritten as

$\Delta p=A \cdot(m \cdot \lambda \cdot Q)^{\beta_{1}} \cdot\left(\frac{1}{V_{\mathrm{I}}}\right)^{\beta_{1}} \cdot\left(\frac{V_{\mathrm{I}}}{V_{\mathrm{I}}+V_{\mathrm{II}}}\right)^{\beta_{2}} \cdot\left(\frac{V_{\mathrm{I}}+V_{\mathrm{II}}}{V}\right)^{\beta_{3}}$.

The overpressure in Zone IV can be expressed as

$$
\begin{aligned}
\Delta p= & A \cdot(m \cdot \lambda \cdot Q)^{\beta_{1}} \cdot\left(\frac{1}{V_{\mathrm{I}}}\right)^{\beta_{1}}\left(\frac{V_{\mathrm{I}}}{V_{\mathrm{I}}+V_{\mathrm{II}}}\right)^{\beta_{2}} \\
& \cdot\left(\frac{V_{\mathrm{I}}+V_{\mathrm{II}}}{V_{\mathrm{I}}+V_{\mathrm{II}}+V_{\mathrm{III}}}\right)^{\beta_{3}}\left(\frac{V_{\mathrm{I}}+V_{\mathrm{II}}+V_{\mathrm{III}}}{V}\right)^{\beta_{4}} .
\end{aligned}
$$

If $\beta_{1}, \beta_{2}, \beta_{3}$, and $\beta_{4}$ are the same, equation (11) degenerates to equation (6).

\section{Blasting Scheme Used in the Micangshan Highway Tunnel}

The field tests on the overpressure in a tunnel induced by the blasting were carried out in the Micangshan highway tunnel. If the surrounding rocks of the tunnel were stable, full-face excavation which has a cross-sectional area of $84 \mathrm{~m}^{2}$ (i.e., $12.56 \mathrm{~m}$ in width and $8.7 \mathrm{~m}$ in height) was applied. Figure 3 shows one of the blasting schemes for the full-face excavation of the tunnel. Four kinds of holes are drilled for the blasting: cut holes, stope holes, bottom holes, and contour holes. The cut was used to break out the confinement of the face. Two types of cut are commonly used in tunneling: cuts with angled holes (i.e., conical cut, wedge cut, and fan cut) and with parallel holes (parallel cuts). In this case, the blasting scheme for full-face excavation adopted the parallel cut. After the initial cut creates a second free surface, the stope holes can be blasted at burden into the cut. The bottom holes and the 
contour holes have the task of producing the most exact profile possible by smooth blasting. The diameters of all the holes are $50 \mathrm{~mm}$, and the depths of the holes range from $1.2 \mathrm{~m}$ to $3.5 \mathrm{~m}$ depending on the surrounding rock conditions. Hence, the hole depth and its corresponding explosive charge changes frequently in the tunneling.

The emulsion explosive and delay detonators are used in the blasting. The emulsion explosive has a good water-resistant performance and is widely used in tunneling. Millisecond detonators are also widely used in tunnel blasting because they normally give enough time for the throwing of the fragments and also favorably influence the individual blasts through the overlapping of the ground vibrations and the effect of the gas pressure on the subsequent charges. Table 1 shows the delays of all the detonator series. However, in some cases of small charges, not all the stope holes are drilled or charged, and some detonator series are empty.

A safe distance of blasting operation is necessary in practical tunneling. During the blasting operation, the space in a tunnel can be divided into three parts for the consideration of safety: forbidden area, injury area, and noise area. The forbidden area is close to the explosive charge, where the overpressure and rock fragments induced by the blasting might cause personal injury and property damage. All people and equipment are forbidden to enter this area. The space from the site of the blasting operation to the site where the overpressure is $2 \mathrm{kPa}$ is classified as the injury area. Nonblasting operation personnel must be evacuated out of this area. The noise area is far away from the explosive site, where the overpressure cannot cause personal injury. Hence, personnel can stay in this area and need not move out of the tunnel. It is necessary to determine the border of the injury area accurately for a long tunnel in order to ensure personnel safety and save time in the construction process.

\section{Testing Program}

The following field tests were carried out mainly in the injury area to determine the attenuation parameters $\beta_{1}, \beta_{2}, \beta_{3}$, and $\beta_{4}$. For each blasting operation, the volume of the propagation domain $V\left(\right.$ in $\mathrm{m}^{3}$ ) and the overpressure $\Delta p$ (in $\mathrm{KPa}$ ) were recorded. Generally, two sensors and two acquisition instruments were used at the same time for one test, as shown in Figure 4. $V_{1}$ and $V_{2}$ are the volume of the propagation domain at the sites of sensor 1 and sensor 2 . The acquisition instrument (type: Blast-PRO; manufacturer: Tytest Co., LTD, Chengdu, China) has two channels with a sampling rate $10 \mathrm{k} \sim 4 \mathrm{M}$. The overpressure sensor (model no.: PCB 113B28 SN; manufacturer: PCB Piezotronics, Inc., U.S.) has a measurement range of $344.7 \mathrm{kPa}$ for $\pm 5 \mathrm{~V}$ output and $689.4 \mathrm{kPa}$ for $\pm 10 \mathrm{~V}$ output, a sensitivity of $14.5 \mathrm{mV} /$ $\mathrm{kPa}$, and a resolution of $0.007 \mathrm{kPa}$. The testing scheme is shown in Figure 4.

The overpressure sensors and acquisition instruments are placed near the side wall of the tunnel, and no obstacles are nearby. Figure 5 shows the field tests in the Micangshan tunnel.

The distance between the two sensors has to be large enough to acquire the whole attenuation. And then, the attenuation of the overpressure from the location of sensor 1 to the location of sensor 2 can be calculated. As is shown in Figure 4, the distance between the two sensors should be longer than $50 \mathrm{~m}$ to avoid the interference. For a certain blasting operation, the overpressures $\Delta p_{1}$ and $\Delta p_{2}$ at the sites of sensor 1 and sensor 2 can be predicted by equation (6), and the attenuation of the overpressure can be drawn:

$$
\frac{\Delta p_{2}}{\Delta p_{1}}=\left(\frac{V_{1}}{V_{2}}\right)^{\beta},
$$

where $V_{1}$ and $V_{2}$ can be calculated by the product of the area of the cross section and the distance from the face to the acquisition instrument.

\section{Testing Results}

Figure 6 shows the waveforms acquired by the sensors after a blast. The blast waveforms have its own characteristics. It is different from the waves produced by other causes, such as tunnel vehicle load and metro train [33]. Each peak reflects the explosion of a detonator series. Generally, cut holes have the maximum charge. The cut holes blasted first and induced the strongest overpressure. The stope holes are followed by the cut holes. The bottom holes and the contour holes had the minimum charge and blasted last. Hence, the maximum peak of the overpressure is decided by the charge of the cut holes. In order to control the variables, we take the maximum peak of the overpressure as $\Delta p$ in the test results.

The test results are shown in Table 2. Tests were done five times in each zone, and two sensors are placed at a distance of parameter $l$ in each test. The length of Zone $\mathrm{I}$ is about $80 \sim 90 \mathrm{~m}$. The parameter $l$ in Zone I is $50 \mathrm{~m}$. The approximate length of Zone II is $40 \sim 50 \mathrm{~m}$. In the test, to measure the whole attenuation in Zone II, the sensor 1 was placed 25 meters in front of Zone II. And the sensor 2 was placed 25 meters behind Zone II. So, the parameter $l$ in Zone II is $100 \mathrm{~m}$. The length of Zone III is extremely long, and the two sensors can both be placed in Zone III. The parameter $l$ in Zone III is $200 \mathrm{~m}$. As for Zone IV, the length of Zone IV is about $40 \mathrm{~m}$. Because the effect of attenuation in Zone III is not obvious, the sensors could be placed in Zone III to acquire the whole attenuation in Zone IV. During the field testing, the sensor 1 was placed $55 \mathrm{~m}$ in front of Zone IV. The sensor 2 was placed $55 \mathrm{~m}$ behind Zone IV. So, the parameter $l$ in Zone IV is $150 \mathrm{~m}$. The parameter $L_{1}$ represents the distance from the work face to the front sensor at that test moment. The parameter $L_{2}$ represents the distance from the work face to the latter sensor at that test moment. In terms of equation (12), every test location could provide a parameter $\beta$.

After averaging the results from the five tests in each zone, the results are as follows: parameter $\beta_{1}$ is 0.515 for Zone I, parameter $\beta_{2}$ is 2.66 for Zone II, parameter $\beta_{3}$ is 0.29 for Zone III, and parameter $\beta_{4}$ is 4.45 for Zone IV. The order of attenuation of overpressure in the four zones is Zone IV $>$ Zone II $>$ Zone I $>$ Zone III.

The parameter $\beta$ is related to the change of cross-sectional area, roughness of the wall, and the obstacles in the tunnel. The tunnel has rough and uneven wall in Zone I and 


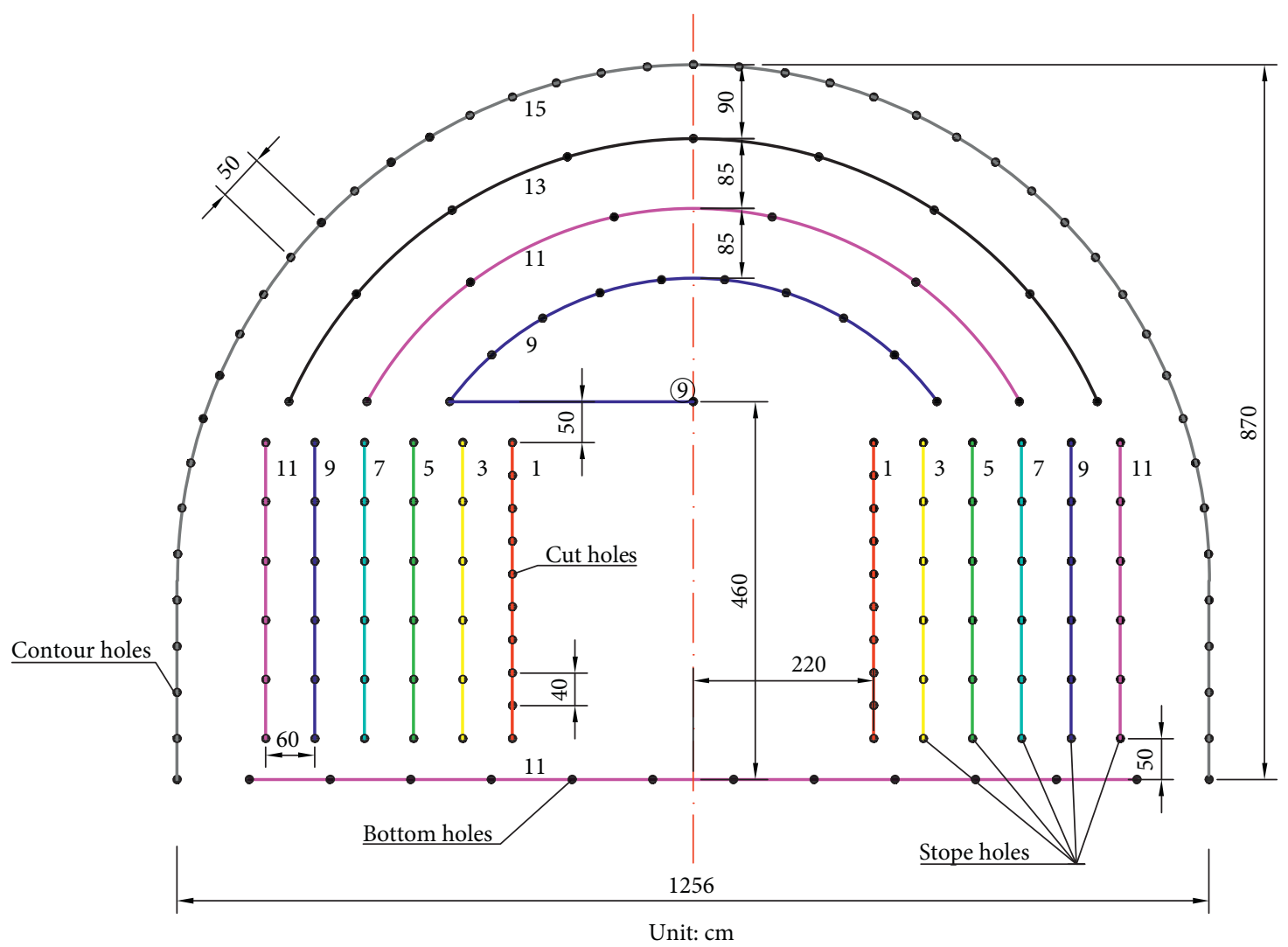

Figure 3: Typical blasting scheme for full-face excavation.

TABle 1: Delays with different detonator series.

\begin{tabular}{|c|c|c|c|c|c|c|c|c|c|c|c|c|c|c|c|}
\hline Detonator series & 1 & 2 & 3 & 4 & 5 & 6 & 7 & 8 & 9 & 10 & 11 & 12 & 13 & 14 & 15 \\
\hline Delay (ms) & 0 & 25 & 50 & 75 & 110 & 150 & 200 & 250 & 310 & 380 & 460 & 550 & 650 & 760 & 880 \\
\hline
\end{tabular}

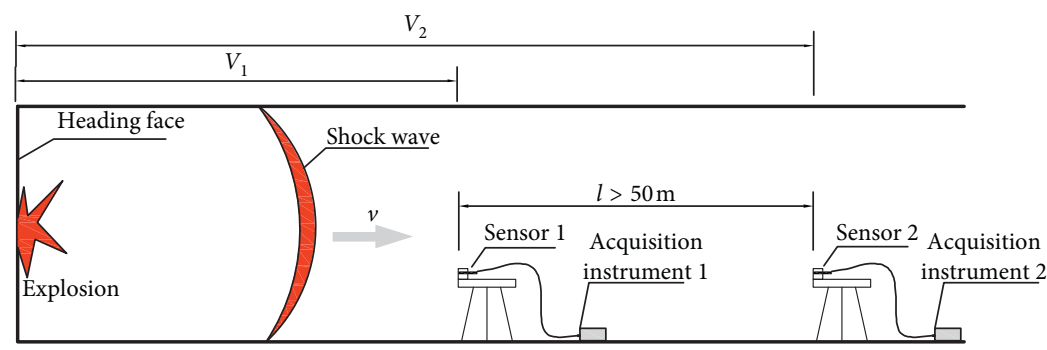

(a)

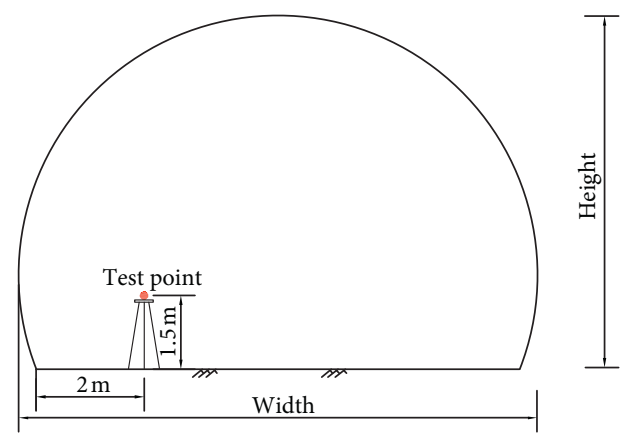

(b)

Figure 4: Testing scheme.

has smooth surface in Zone III. By comparing with Zone I and Zone III, it can be seen that the rougher the wall is, the greater the attenuation parameter $\beta$ is. In Zone II, there are many working machines placed, such as the framework of the secondary lining casting, loaders. By comparing with Zone I and Zone II, it can be seen that the attenuation parameter $\beta$ is greater when there are obstacles in the tunnel. In Zone IV, the tunnel has an enlarged cross section and cross aisle. By comparing with Zone III and Zone IV, it can be seen that the attenuation parameter $\beta$ is greater when there is change of the cross-sectional area and the branch of the tunnel.

Figure 7 shows the correlation of the overpressure in Zone I and Zone III between the tested values and the calculated values. In Zone I, the modified equation is the 


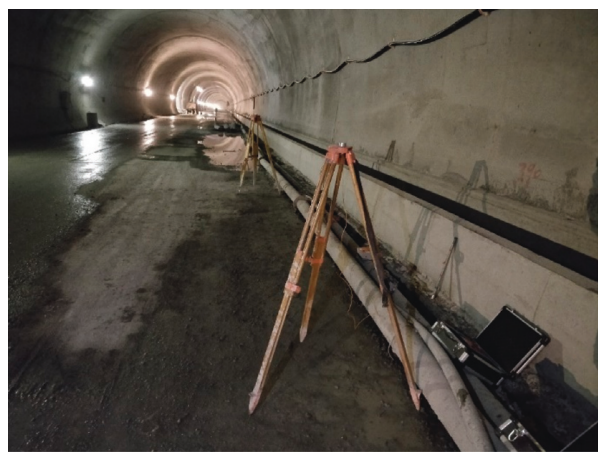

(a)

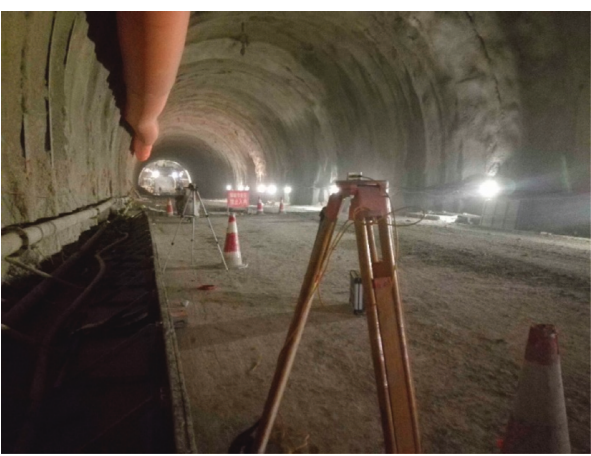

(b)

Figure 5: Photos of the testing.

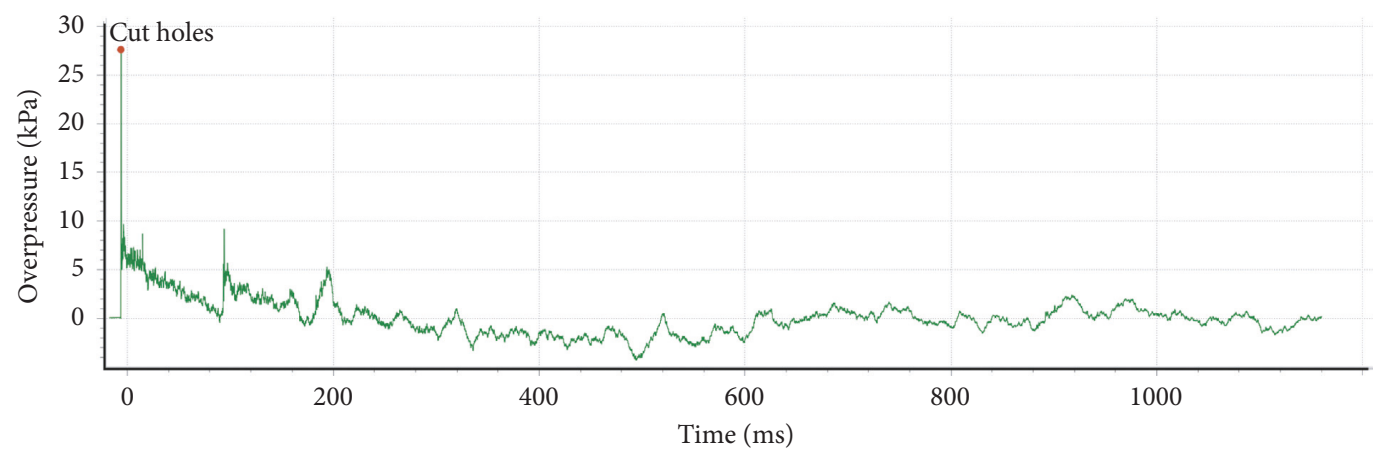

(a)

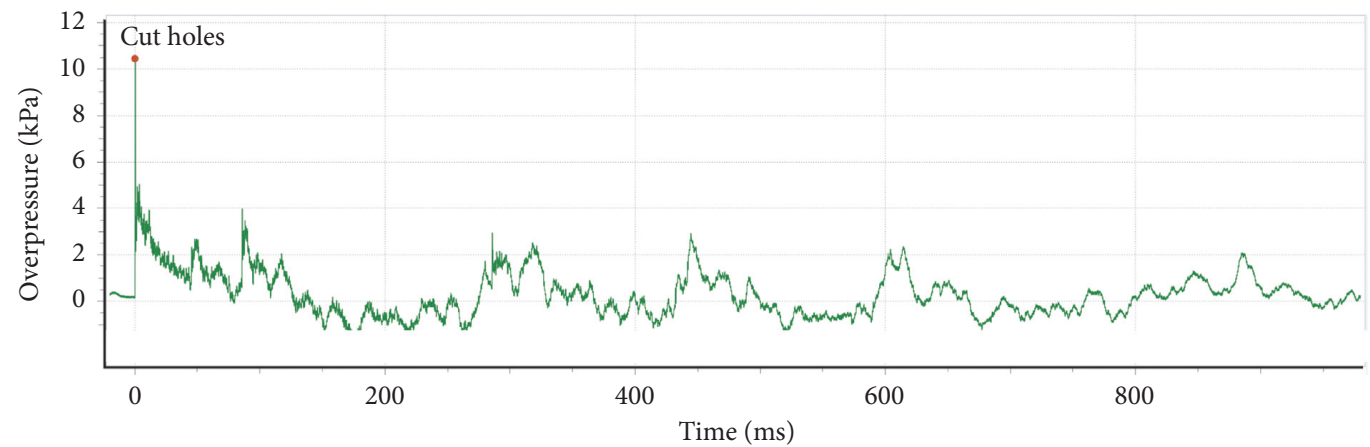

(b)

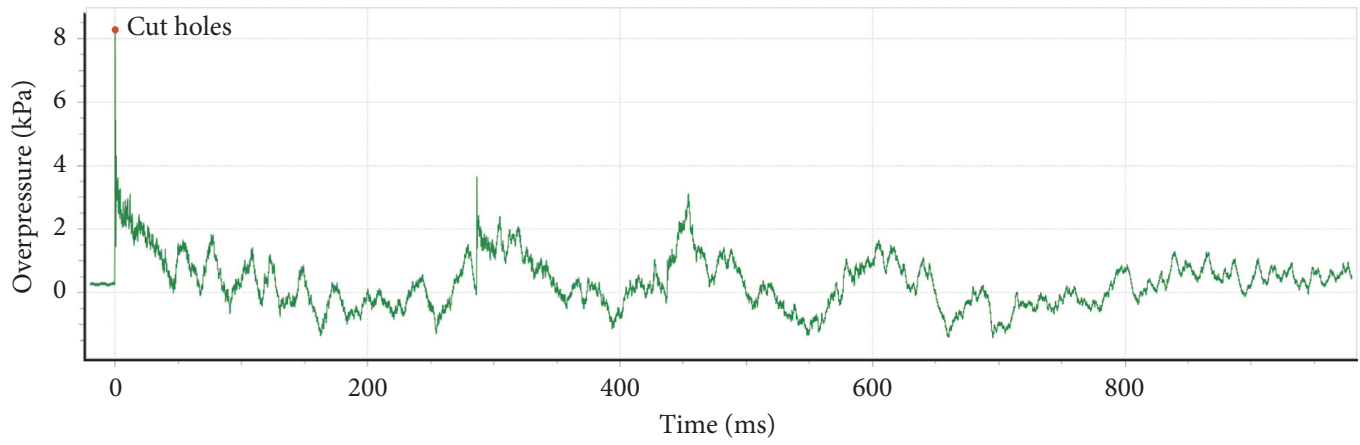

(c)

Figure 6: Continued. 


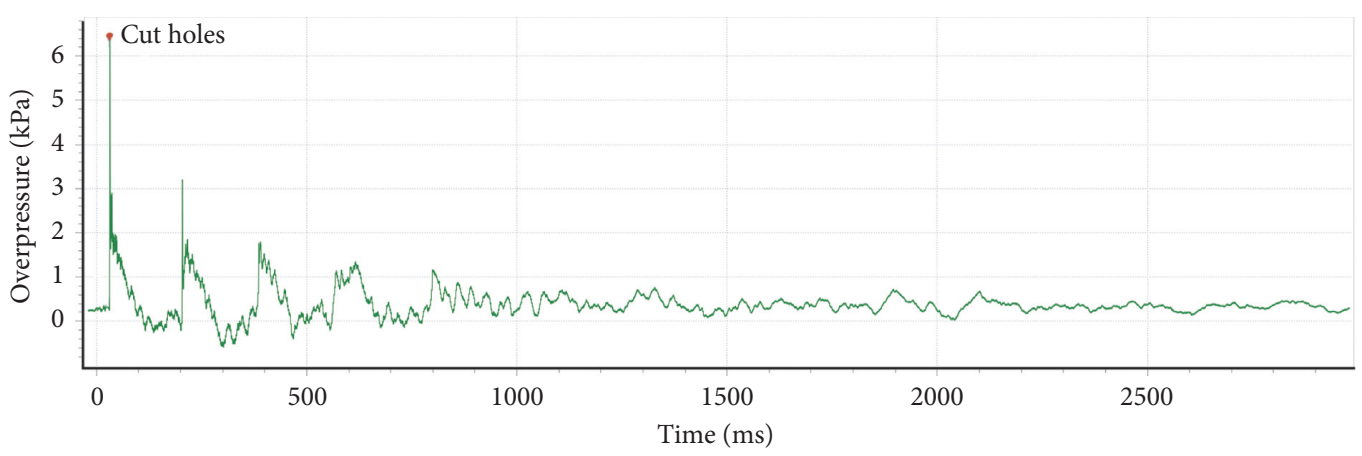

(d)

FIGURE 6: Shock waves test waveform. (a) Zone I. (b) Zone II. (c) Zone III. (d) Zone IV.

TABLE 2: Overpressure in the tunnel induced by blasting.

\begin{tabular}{|c|c|c|c|c|c|c|c|c|c|c|}
\hline Zone no. & Test no. & $\Delta p_{1}(\mathrm{kPa})$ & $\Delta p_{2}(\mathrm{kPa})$ & $V_{1}\left(\mathrm{~m}^{3}\right)$ & $V_{2}\left(\mathrm{~m}^{3}\right)$ & $l(\mathrm{~m})$ & $L_{1}(\mathrm{~m})$ & $L_{2}(\mathrm{~m})$ & Exponential $\beta$ & Mean of $\beta$ \\
\hline \multirow{5}{*}{ Zone I } & $1-1$ & 26.803 & 23.762 & 14972 & 18871 & 50 & 192 & 242 & 0.520 & \multirow{5}{*}{$\beta_{1}=0.515$} \\
\hline & $1-2$ & 22.388 & 19.503 & 12555 & 16454 & 50 & 161 & 211 & 0.509 & \\
\hline & $1-3$ & 36.814 & 32.094 & 12945 & 16844 & 50 & 166 & 216 & 0.521 & \\
\hline & $1-4$ & 29.190 & 25.250 & 11697 & 15596 & 50 & 150 & 200 & 0.504 & \\
\hline & $1-5$ & 25.837 & 22.587 & 13256 & 17156 & 50 & 170 & 220 & 0.521 & \\
\hline \multirow{5}{*}{ Zone II } & $2-1$ & 19.080 & 9.849 & 20665 & 27381 & 100 & 265 & 365 & 2.350 & \multirow{5}{*}{$\beta_{2}=2.66$} \\
\hline & $2-2$ & 20.105 & 10.026 & 20899 & 27615 & 100 & 268 & 368 & 2.497 & \\
\hline & $2-3$ & 16.359 & 7.720 & 21289 & 28005 & 100 & 273 & 373 & 2.739 & \\
\hline & $2-4$ & 15.908 & 6.815 & 20275 & 26991 & 100 & 251 & 351 & 2.963 & \\
\hline & $2-5$ & 18.670 & 7.921 & 18403 & 25120 & 100 & 236 & 336 & 2.756 & \\
\hline \multirow{5}{*}{ Zone III } & $3-1$ & 8.583 & 7.881 & 25254 & 37760 & 200 & 350 & 550 & 0.212 & \multirow{5}{*}{$\beta_{3}=0.29$} \\
\hline & $3-2$ & 10.494 & 9.109 & 23373 & 35879 & 200 & 314 & 514 & 0.330 & \\
\hline & $3-3$ & 8.259 & 7.350 & 24310 & 36816 & 200 & 327 & 527 & 0.281 & \\
\hline & $3-4$ & 7.595 & 6.608 & 25126 & 37632 & 200 & 335 & 535 & 0.345 & \\
\hline & $3-5$ & 9.859 & 8.828 & 26437 & 38943 & 200 & 363 & 563 & 0.285 & \\
\hline \multirow{5}{*}{ Zone IV } & $4-1$ & 6.456 & 1.561 & 36614 & 49235 & 150 & 525 & 675 & 4.793 & \multirow{5}{*}{$\beta_{4}=4.45$} \\
\hline & $4-2$ & 5.625 & 1.655 & 36614 & 49235 & 150 & 525 & 675 & 4.131 & \\
\hline & 4-3 & 7.259 & 1.989 & 36880 & 49521 & 150 & 530 & 680 & 4.393 & \\
\hline & 4-4 & 5.936 & 1.289 & 31877 & 44498 & 150 & 550 & 700 & 4.583 & \\
\hline & 4-5 & 7.853 & 2.205 & 37067 & 49688 & 150 & 533 & 683 & 4.335 & \\
\hline
\end{tabular}

same as the original equation. According to the test results, the exponential $\beta_{1}$ is 0.515 in the modified equation and the exponential $\beta$ is 0.514 in the original equation. So, the fit lines are basically coincident: the $R^{2}$ coefficients for the modified equation and the original equation are 0.6698 and 0.6699 , respectively. In Zone III, the $R^{2}$ coefficients for the modified equation and the original equation are 0.5474 and 0.4766 , respectively. The modified equation takes resistance factors into account and uses different exponentials to indicate these factors. Therefore, the $R^{2}$ coefficient of the modified equation is larger than that of the original equation.

Comparing the two $R^{2}$ coefficients of the original equation and the modified equation indicates the necessity of dividing the tunnel into different zones to research the attenuation of the overpressure in the tunnel.

After taking the logarithm of equations (7) and (10), the overpressure ln $\Delta p$ can be calculated by the two variables: explosive charge $Q$ and volume $V$. Figure 8 shows the relationship of the planes that pass the overpressure ln $\Delta p$. In Zone I, the two planes that pass $\ln \Delta p$ as calculated by the modified equation and original equation are coincident. In Zone III, due to the impact of $\beta_{2}$ and $\beta_{3}$, it can be seen that the slope of the plane which passes ln $\Delta p$ calculated by the modified equation has changed.

\section{Conclusion and Discussion}

Using the equation $\Delta p=A \cdot(Q / V)^{\beta}$ put forward by Smith and Sapko [29], this paper considers many factors such as the change of cross-sectional area, roughness of the wall, and obstacles in the tunnel and modifies the equation accordingly. When blast waves propagate in the tunnel, the tunnel can be divided into several zones. The degree of attenuation of overpressure in each zone is distinct, and a constant value of the exponential $\beta$ cannot represent all the conditions along the tunnel. Therefore, there are different attenuation equations and exponential $\beta$ in each zone.

This theory is applied in the Micangshan highway tunnel in China. The tunnel is divided into four zones. In Zone $\mathrm{I}$, the overpressure can be expressed as $\Delta p=A \cdot(m \cdot \lambda \cdot Q / V)^{\beta_{1}}$, 


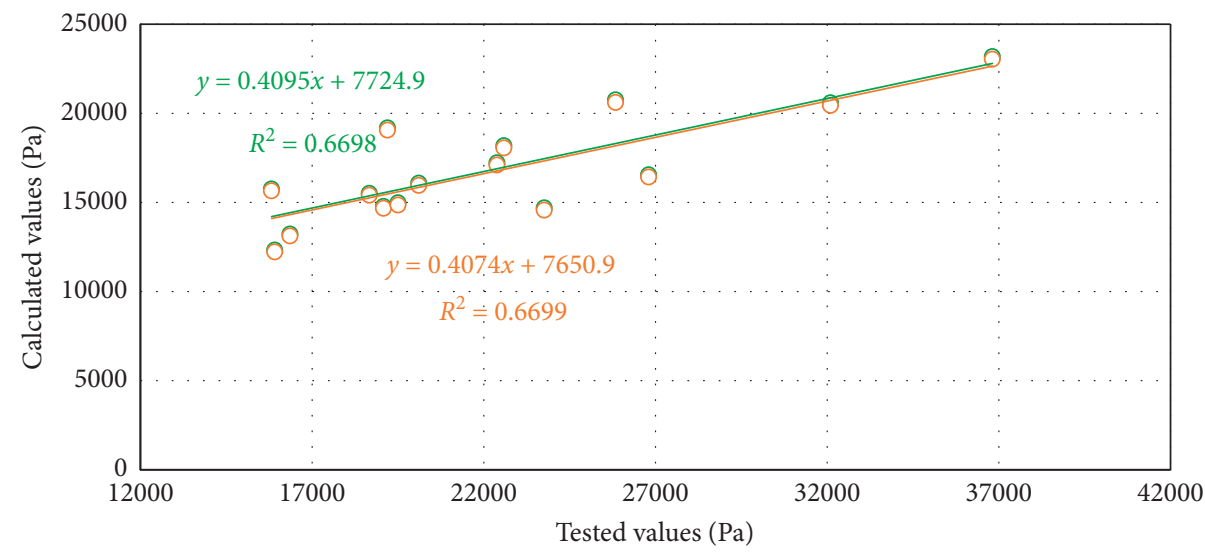

O Original equation

$\circ$ Modified equation

(a)

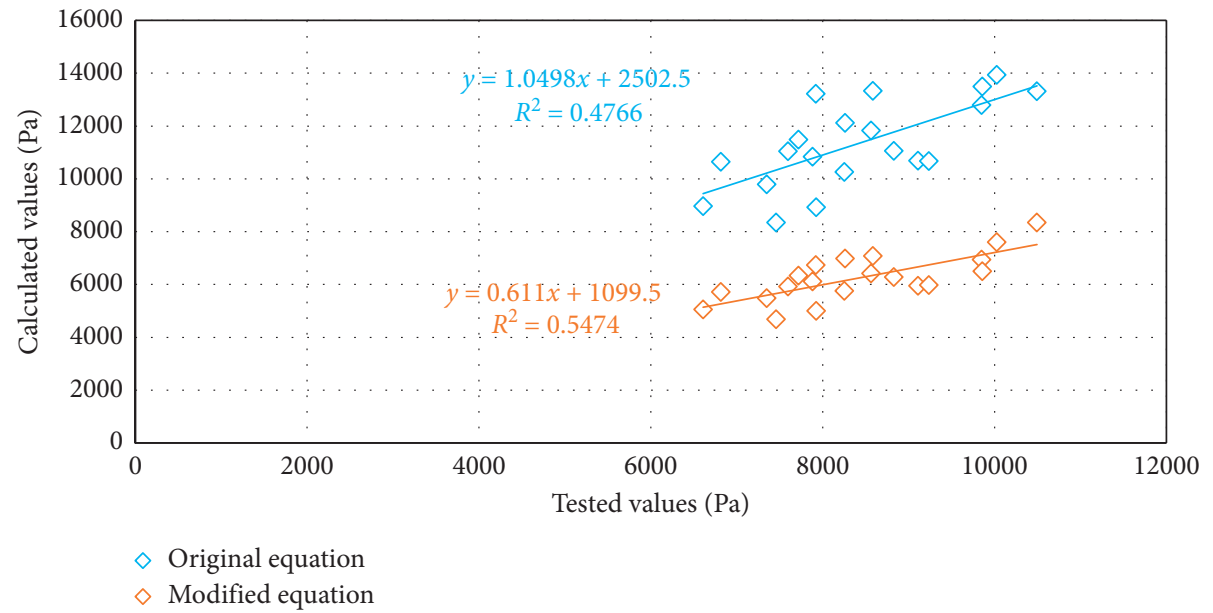

(b)

FIgURE 7: Correlation of overpressure between calculated values and tested values. (a) Zone I. (b) Zone III.

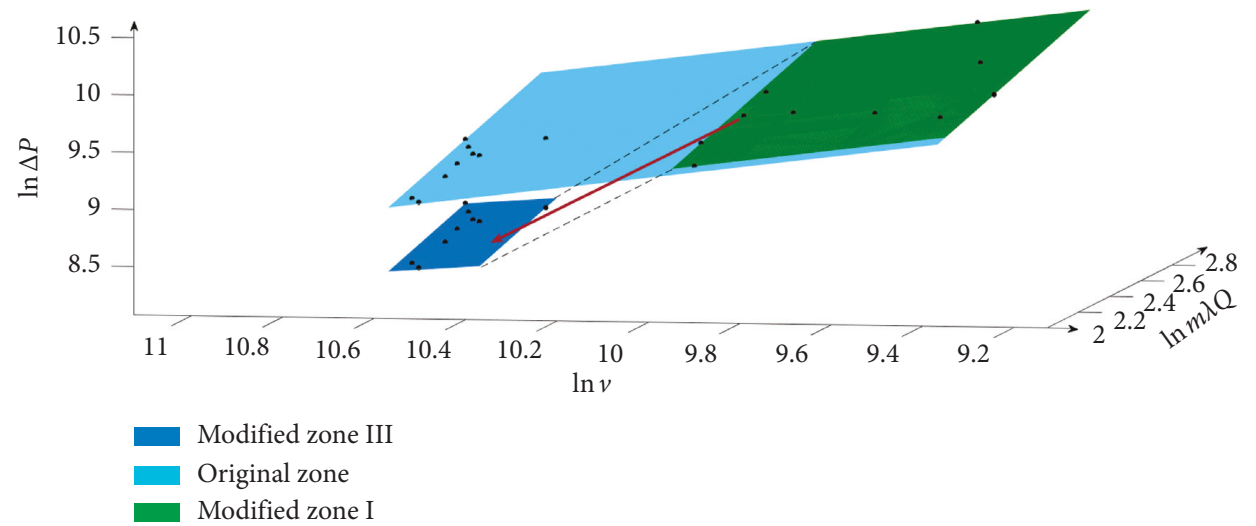

FIGURE 8: $\ln \Delta p$ calculated by the modified equation and original equation in Zone I and Zone III.

where $V$ is the whole volume of the propagation domain and $\beta_{1}$ is the attenuation exponential in Zone I. In Zone II, the overpressure can be expressed as $\Delta p=A \cdot(m \cdot \lambda$. $\left.\mathrm{Q} / V_{\mathrm{I}}\right)^{\beta_{1}} \cdot\left(V_{\mathrm{I}} / V\right)^{\beta_{2}}$, where $V_{\mathrm{I}}$ is the whole volume of Zone I. In Zone III, the overpressure can be expressed as $\Delta p=A$. $\left(m \cdot \lambda \cdot Q / V_{\mathrm{I}}\right)^{\beta_{1}} \cdot\left(V_{\mathrm{I}} /\left(V_{\mathrm{I}}+V_{\mathrm{II}}\right)\right)^{\beta_{2}} \cdot\left(\left(V_{\mathrm{I}}+V_{\mathrm{II}}\right) / V\right)^{\beta_{3}}$, where $V_{\text {II }}$ is the whole volume of Zone II. In Zone IV, the overpressure can be expressed as $\Delta p=A \cdot(m \cdot \lambda \cdot Q)^{\beta_{1}} \cdot\left(1 / V_{\mathrm{I}}\right)^{\beta_{1}}$. $\left(V_{\mathrm{I}} /\left(V_{\mathrm{I}}+V_{\text {II }}\right)\right)^{\beta_{2}} \cdot\left(\left(V_{\mathrm{I}}+V_{\text {II }}\right) /\left(V_{\mathrm{I}}+V_{\text {II }}+V_{\text {III }}\right)\right)^{\beta_{3}}\left(\left(V_{\mathrm{I}}+V_{\text {II }}+\right.\right.$ $\left.V_{\text {III }} / V\right)^{\beta_{4}}$, where $V_{\text {III }}$ is the whole volume of Zone III. 
From the field tests about overpressure in the Micangshan highway tunnel and the calculation of volume, the exponential $\beta$ can be determined as follows: $\beta_{1}=0.515$, $\beta_{2}=2.66, \beta_{3}=0.29$, and $\beta_{4}=4.45$. In Zone I, the $R^{2}$ coefficients are almost the same between the modified equation and the original equation for the tested values and calculation values, while in Zone III, the $R^{2}$ coefficient of the modified equation is better than that of the original equation.

However, when the modified equation is applied from Zone I to Zone III, it reflects the change of slope in the planes that pass the overpressure. The equation could be modified further at a later time to reflect the change of the slope in a straight line from Zone I to Zone III.

\section{Data Availability}

The data used to support the findings of this study are included within the article.

\section{Conflicts of Interest}

The authors declare that they have no conflicts of interest.

\section{Acknowledgments}

This research was funded by the National Key Research and Development Program of China (no. 2016YFC0802205) and the National Natural Science Foundation of China (nos. 51578460 and 51678499).

\section{References}

[1] R. P. Dhakal and T.-C. Pan, "Response characteristics of structures subjected to blasting-induced ground motion," International Journal of Impact Engineering, vol. 28, no. 8, pp. 813-828, 2003.

[2] L. Tian and Z.-X. Li, "Dynamic response analysis of a building structure subjected to ground shock from a tunnel explosion," International Journal of Impact Engineering, vol. 35, no. 10, pp. 1164-1178, 2008.

[3] J. H. Yang, W. B. Lu, Q. H. Jiang, C. Yao, and C. B. Zhou, "Frequency comparison of blast-induced vibration per delay for the full-face millisecond delay blasting in underground opening excavation," Tunnelling and Underground Space Technology, vol. 51, pp. 189-201, 2016.

[4] L. B. Jayasinghe, H. Y. Zhou, A. T. C. Goh, Z. Y. Zhao, and Y. L. Gui, "Pile response subjected to rock blasting induced ground vibration near soil-rock interface," Computers and Geotechnics, vol. 82, pp. 1-15, 2017.

[5] X. G. Wang, Y. L. Yu, and D. Z. Liu, Enforceable Handbook of Safety Regulations for Blasting, China Communication Press, Beijing, China, 2004.

[6] R. Rodríguez, J. Toraño, and M. Menéndez, "Prediction of the airblast wave effects near a tunnel advanced by drilling and blasting," Tunnelling and Underground Space Technology, vol. 22, no. 3, pp. 241-251, 2007.

[7] W. E. Baker, P. A. Cox, P. S. Westine, J. J. Kulesz, and R. A. Strehlow, "Explosion hazards and evaluation," in Fundamental Studies in Engineering, Elsevier, New York, NY, USA, 1983.
[8] Y. Fang, J. Fan, B. Kenneally, and M. Mooney, "Air flow behavior and gas dispersion in the recirculation ventilation system of a twin-tunnel construction," Tunnelling and Underground Space Technology, vol. 58, pp. 30-39, 2016.

[9] H. L. Brode, "Blast wave from a spherical charge," Physics of Fluids, vol. 2, no. 2, pp. 217-229, 1959.

[10] J. Henrych, The Dynamics of Explosion and Its Use, Elsevier Press, Amsterdam, Netherlands, 1979.

[11] N. Ishikawa and M. Beppu, "Lessons from past explosive tests on protective structures in Japan," International Journal of Impact Engineering, vol. 34, no. 9, pp. 1535-1545, 2007.

[12] T. C. Chapman, T. A. Rose, and P. D. Smith, "Blast wave simulation using AUTODYN2D: a parametric study," International Journal of Impact Engineering, vol. 16, no. 5-6, pp. 777-787, 1995.

[13] C. Wu and H. Hao, "Numerical simulation of structural response and damage to simultaneous ground shock and airblast loads," International Journal of Impact Engineering, vol. 34, no. 3, pp. 556-572, 2007.

[14] J. Casal and J. M. Salla, "Using liquid superheating energy for a quick estimation of overpressure in BLEVEs and similar explosions," Journal of Hazardous Materials, vol. 137, no. 3, pp. 1321-1327, 2006.

[15] B. Genova, M. Silvestrini, and F. J. Leon Trujillo, "Evaluation of the blast-wave overpressure and fragments initial velocity for a BLEVE event via empirical correlations derived by a simplified model of released energy," Journal of Loss Prevention in the Process Industries, vol. 21, no. 1, pp. 110-117, 2008.

[16] P. D. Smith, G. C. Mays, T. A. Rose, K. G. Teo, and B. J. Roberts, "Small scale models of complex geometry for blast overpressure assessment," International Journal of Impact Engineering, vol. 12, no. 3, pp. 345-360, 1992.

[17] P. D. Smith, P. Vismeg, L. C. Teo, and L. Tingey, "Blast wave transmission along rough-walled tunnels," International Journal of Impact Engineering, vol. 21, no. 6, pp. 419-432, 1998.

[18] X. Li and Y. Zheng, "In-tunnel blast pressure empirical equations for detonations external, internal and at the tunnel entrance," Transactions of Tianjin University, vol. 12, pp. 177-181, 2006.

[19] J. M. Powers and H. Krier, "Attenuation of blast waves when detonating explosives inside barriers," Journal of Hazardous Materials, vol. 13, no. 2, pp. 121-133, 1986.

[20] T. Huld, G. Peter, and H. Städtke, "Numerical simulation of explosion phenomena in industrial environments," Journal of Hazardous Materials, vol. 46, no. 2-3, pp. 185-195, 1996.

[21] F. Rigas and S. Sklavounos, "Experimentally validated 3-D simulation of shock waves generated by dense explosives in confined complex geometries," Journal of Hazardous Materials, vol. 121, no. 1-3, pp. 23-30, 2005.

[22] A. M. Benselama, M. J.-P. William-Louis, and F. Monnoyer, "A 1D-3D mixed method for the numerical simulation of blast waves in confined geometries," Journal of Computational Physics, vol. 228, no. 18, pp. 6796-6810, 2009.

[23] J. Liu, Q. Yan, and J. Wu, "Analysis of blast wave propagation inside tunnel," Transactions of Tianjin University, vol. 14, no. 5, pp. 358-362, 2008.

[24] A. M. Benselama, M. J.-P. William-Louis, F. Monnoyer, and C. Proust, "A numerical study of the evolution of the blast wave shape in tunnels," Journal of Hazardous Materials, vol. 181, no. 1-3, pp. 609-616, 2010.

[25] D. Uystepruyst and F. Monnoyer, "A numerical study of the evolution of the blast wave shape in rectangular tunnels," 
Journal of Loss Prevention in the Process Industries, vol. 34, pp. 225-231, 2015.

[26] O. Pennetier, M. William-Louis, and A. Langlet, "Numerical and reduced-scale experimental investigation of blast wave shape in underground transportation infrastructure," Process Safety and Environmental Protection, vol. 94, pp. 96-104, 2015.

[27] R. Rodríguez, C. Lombardía, and S. Torno, "Prediction of the air wave due to blasting inside tunnels: approximation to a 'phonometric curve'," Tunnelling and Underground Space Technology, vol. 25, no. 4, pp. 483-489, 2010.

[28] R. J. Mainiero and E. S. Weiss, "Blast wave propagation in underground mines," in Proceedings of the 11th Annual Symposium on Explosives and Blasting Research, Nashville, TN, USA, February 1995.

[29] A. C. Smith and M. J. Sapko, "Detonation wave propagation in underground mine entries," Journal of the Mine Ventilation Society of South Africa, vol. 58, pp. 20-25, 2005.

[30] G. W. Kuzyk, "Overpressure generation and control in tunnel blasts", in Proceedings of the Innovative Mine Design for the 21st Century, W. F. Bawen, J. F. Archibald, A. A. Balkema, Eds., p. 527, Rotterdam, Netherlands, August 1993.

[31] M. Silvestrini, B. Genova, and F. J. Leon Trujillo, "Energy concentration factor. A simple concept for the prediction of blast propagation in partially confined geometries," Journal of Loss Prevention in the Process Industries, vol. 22, no. 4, pp. 449-454, 2009.

[32] J. Fan, Q. Fang, Y. Zhang, and L. Chen, "Experimental investigation on the TNT equivalence coefficient of a rock emulsion explosive," Acta Armamentarii, vol. 32, no. 10, pp. 1243-1249, 2011

[33] J. Lai, K. Wang, J. Qiu, F. Niu, J. Wang, and J. Chen, "Vibration response characteristics of the cross tunnel structure," Shock and Vibration, vol. 2016, Article ID 9524206, 16 pages, 2016. 


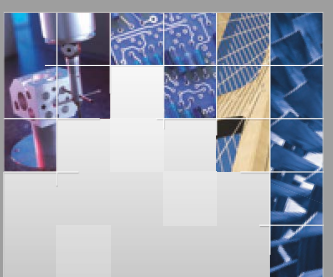

\section{Enfincering}
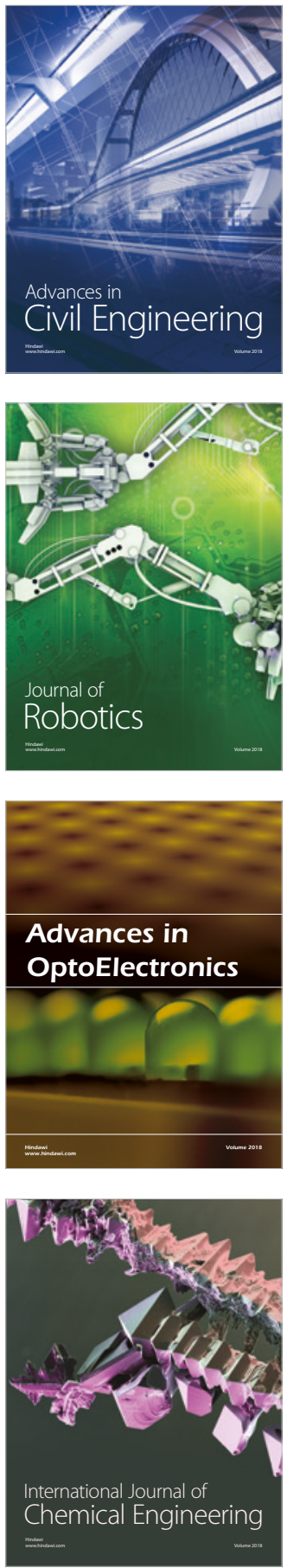

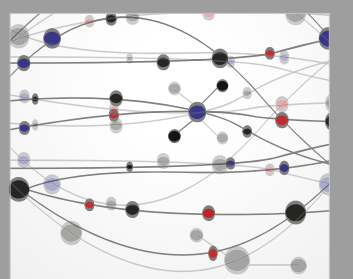

\section{Rotating \\ Machinery}

The Scientific World Journal

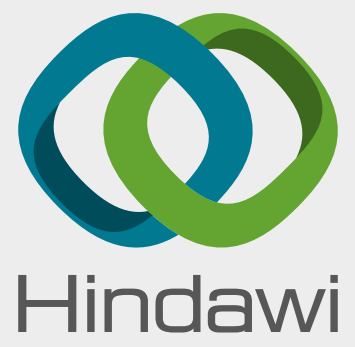

Submit your manuscripts at

www.hindawi.com
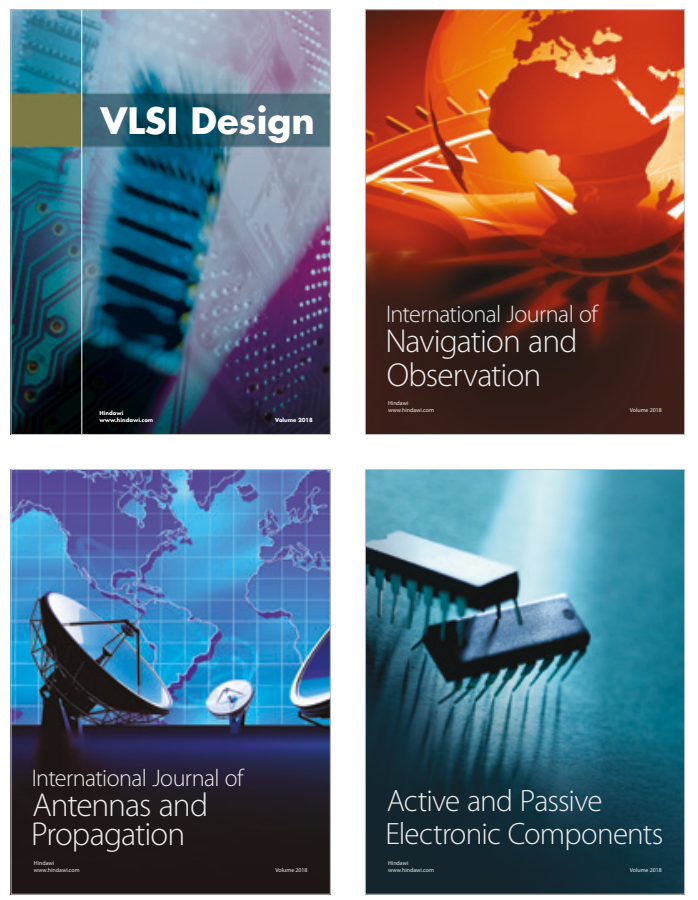
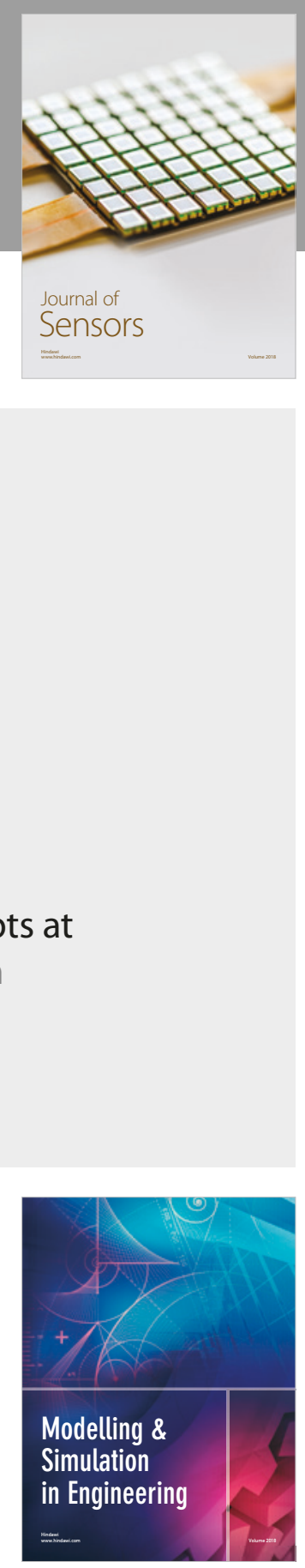

\section{Advances \\ Multimedia}
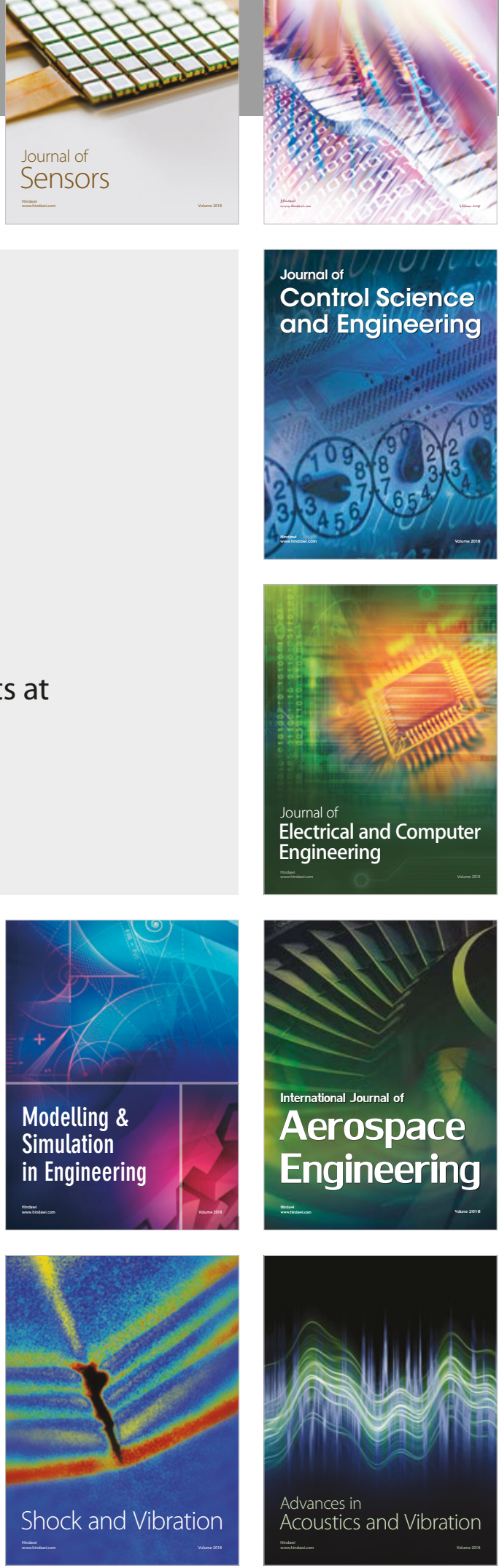